\title{
Accelerated partial breast irradiation: advances and controversies
}

\author{
Mani Akhtari ${ }^{1,2}$ and Bin S. Teh ${ }^{1 *}$
}

\begin{abstract}
The management of localized breast cancer has changed dramatically over the past three to four decades. Breastconserving therapy, which involved lumpectomy followed by adjuvant irradiation, is now widely considered the standard of care in women with early-stage breast cancer. Accelerated partial breast irradiation (APBI), which involves focal irradiation of the lumpectomy cavity over a short period of time, has developed over the past two decades as an alternative to whole breast irradiation (WBI). Multiple APBI modalities have been developed including brachytherapy, external beam irradiation, and intraoperative irradiation. These new techniques have provided early-stage breast cancer patients with shorter treatment duration and more focused irradiation, delivering very high biological doses to the region at a high risk of failures over a much shorter treatment course as compared with conventional radiotherapy. However, the advantages of APBI over conventional radiotherapy are controversial, including a higher risk of complications reported in retrospective literature and shorter follow-up duration in the intraoperative APBI trials. Nevertheless, APBI presents a valuable alternative to WBI for a selected population of women with early-stage breast cancer.
\end{abstract}

Keywords: Accelerated partial breast irradiation, Brachytherapy, Breast cancer

\section{Background}

The management of localized breast cancer has changed dramatically over the past three to four decades. Mastectomy, the initial management of this disease, has shifted increasingly towards breast-conserving therapies (BCT) after landmark trials such as the National Surgical Adjuvant Breast and Bowel Project B-06 [1], Milan [2], and the European Organization for Research and Treatment of Cancer 10801 [3] showed that mastectomy was equivalent to breast-conserving surgery (BCS) followed by postoperative irradiation. In these trials, the addition of whole breast irradiation (WBI) after BCS decreased the chance of ipsilateral breast tumor recurrence by $50 \%$ or more, indicating the need for radiotherapy to address any residual microscopic disease. However, WBI usually consists of 5-6 weeks of daily irradiation, which can impose certain logistical, economical, and social barriers to care. In fact, in women who undergo BCS, the percentage of

\footnotetext{
*Correspondence: bteh@houstonmethodist.org

${ }^{1}$ Department of Radiation Oncology, Houston Methodist Hospital, Cancer Center and Research Institute, Weil Cornell Medical College, 6565 Fannin, Ste\#DB1-077, Houston, TX 77030, USA

Full list of author information is available at the end of the article
}

patients who undergo radiotherapy can vary from $12 \%$ to $77 \%$ depending on their age, access to a radiation therapy center, and comorbidities [4]. Additionally, $68 \%$ of ipsilateral breast tumor recurrences are within $3 \mathrm{~cm}$ from the primary tumor, emphasizing the need to focus around the area of the initial disease and raising the necessity of irradiation on the whole breast of patients with early-stage breast cancer. This has led to development of techniques that shorten the courses of radiation to the immediate area surrounding the tumor bed. Due to the decreased number of irradiation fractions, shortened treatment duration, and decreased size of the irradiation field, this group of treatments is collectively named accelerated partial breast irradiation (APBI).

\section{Brachytherapy in APBI}

One of the most widely used APBI approaches is via brachytherapy (B-APBI), which involves placement of radioactive sources into the breast tissue to deliver high doses of radiation to a confined area. Here we discuss the different forms of B-APBI and the existing data justifying their safety and efficacy. 


\section{Interstitial brachytherapy}

Interstitial brachytherapy is the first technique developed and used to treat only a partial amount of breast tissue. Although the first published series of interstitial brachytherapy date back to 1920 s, breast interstitial brachytherapy did not come into prominence until the 1970s [5]. At that time, BCT was being developed, and since no electron beam therapy was available, a boost was given to the vicinity of the tumor bed using low-dose-rate (LDR) interstitial brachytherapy. With the advent of high-energy linear accelerators, electron beam boosts for the most part supplanted interstitial brachytherapy. However, in the meantime, brachytherapy techniques also improved dramatically along with better dose homogeneity, resulting in improved overall cosmesis [6]. As the experience with interstitial brachytherapy for boost grew, several trials were undertaken to evaluate its safety and efficacy as the sole modality of irradiation after BCS.

To date, numerous single-arm and some randomized studies have been conducted examining multi-catheter interstitial brachytherapy. The results of the most important trials are summarized in Table 1 [7-14]. Most of these studies enrolled patients with early-stage breast cancer, T1 or T2, with some allowing up to three positive axillary lymph nodes (N1). All studies required negative surgical margins and the majority of the trials excluded women with lobular or ductal carcinoma in situ (LCIS or DCIS) histology. Interstitial catheters were placed anywhere from 4 to 8 weeks after surgery using either a free-hand technique or a breast template with the placed surgical clips as a point of guidance. Some of the later studies used 3-dimensional planning. Consistent with the general trends in overall use of brachytherapy, a percentage of earlier patients were treated with LDR or pulsed-dose-rate (PDR) sources, but the majority of the more recent patients were treated using ${ }^{192}$ Iridium $\left({ }^{192}\right.$ Ir) high-dose-rate (HDR) brachytherapy. In almost all of the studies, the tumor bed plus $2 \mathrm{~cm}$ (some 1-2 cm) was covered by the radiation. LDR doses ranged from 45 to 50 Gy and HDR from 30 to 36 Gy using twice daily (BID) fractionation. As seen in Table 2 [15-17], with careful patient selection, ipsilateral breast tumor recurrence rates were very low except for that in the Guy's Hospital trial by Fentiman et al. [13], which reported an ipsilateral breast tumor recurrence rate of $18 \%$. The overall cosmesis scores were good to excellent for the majority of the patients with low rates of late complications. Given the promising results of these and earlier studies, APBI slowly became an acceptable option for a limited population of patients with early-stage breast cancer. Its widespread use was however limited by the complicated insertion technique of interstitial brachytherapy catheters.

\section{Single- and multi-lumen applicators}

In 2002, the Food and Drug Administration (FDA) of the United States approved the MammoSite ${ }^{\circledR}$ (Hologic, Bedford, MA, USA) balloon applicator, the first of its kind that simplified catheter insertion and usage of APBI

Table 1 Results of randomized and single-arm interstitial brachytherapy trials

\begin{tabular}{|c|c|c|c|c|c|c|}
\hline Reported trial & Number of patients & $\begin{array}{l}\text { Treatment } \\
\text { volume }\end{array}$ & Source/dose & $\begin{array}{l}\text { Median } \\
\text { follow-up } \\
\text { (months) }\end{array}$ & $\begin{array}{l}\text { Ipsilateral } \\
\text { recurrence } \\
\text { rate (\%) }\end{array}$ & $\begin{array}{l}\text { Outcome/compli- } \\
\text { cations }\end{array}$ \\
\hline Wazer et al. [7] & 32 & $\begin{array}{c}\text { Excision cav- } \\
\text { ity }+2 \mathrm{~cm}\end{array}$ & $\begin{array}{l}{ }^{192} \text { Ir, } 3.4 \text { Gy BID to } \\
34 \text { Gy }\end{array}$ & 33 & 3 & $\begin{array}{l}8 \text { with fat necrosis, } \\
11 \text { with grade } 3-4 \\
\text { skin toxicity }\end{array}$ \\
\hline Arthur et al. [8] & 44 (31 HDR, 13 LDR) & $\begin{array}{l}\text { Lumpectomy cav- } \\
\text { ity }+2 \mathrm{~cm}\end{array}$ & $\begin{array}{l}{ }^{192} \text { Ir, HDR: } 3.4 \text { Gy } \\
\text { BID to } 24 \text { Gy; LDR: } \\
50 \text { cGy/h to } 45 \text { Gy }\end{array}$ & 42 & 0 & $\begin{array}{l}43 \% \text { of LDR patients } \\
\text { had radiation recall } \\
\text { with adriamycin }\end{array}$ \\
\hline Benitez et al. [9] & 199 & $\begin{array}{l}\text { Lumpectomy } \\
\text { bed }+1-2 \mathrm{~cm}\end{array}$ & $\begin{array}{l}\mathrm{LDR}^{125} \mathrm{l}, 0.52 \mathrm{~Gy} / \mathrm{h} \\
\text { to } 50 \mathrm{~Gy} ; \text { HDR }{ }^{192} \mathrm{Ir}, \\
\text { 3.2-3.4 Gy BID to } \\
\text { 32-34 Gy }\end{array}$ & 68.4 & 1.2 & $\begin{array}{l}\text { 11\% fat necrosis, } \\
90 \% \text { good-excel- } \\
\text { lent cosmesis }\end{array}$ \\
\hline Ott et al. [10-12] & 274 & Tumor bed $+2 \mathrm{~cm}$ & $\begin{array}{l}{ }^{192} \text { Ir, PDR: at } 0.6 \text { Gy } \\
\text { pulses to } 50 \text { Gy; } \\
\text { HDR: } 4 \text { Gy BID to } \\
32 \text { Gy }\end{array}$ & 63 & 2.9 & $\begin{array}{l}2.6 \% \geq \text { grade } 3 \text { tox- } \\
\text { icity, } 90 \% \text { good to } \\
\text { excellent cosmesis }\end{array}$ \\
\hline Fentiman et al. [13] & 50 & Tumor bed $+2 \mathrm{~cm}$ & $\begin{array}{l}{ }^{137} \mathrm{Cs}, 4 \text { fractions, } \\
4-6 \text { h/day to } 45 \mathrm{~Gy}\end{array}$ & 75.6 & 18 & $\begin{array}{l}82 \% \text { good to excel- } \\
\text { lent cosmesis }\end{array}$ \\
\hline Polgár et al. [14] & 45 & Tumor bed $+1-2 \mathrm{~cm}$ & $\begin{array}{l}\text { HDR }^{192} / \mathrm{rr}, 7 \text { frac- } \\
\text { tions of } 4.33 \text { or } \\
\text { 5.2 Gy in } 4 \text { days to } \\
\text { 30.3-36.4 Gy }\end{array}$ & 133 & 8.9 & $\begin{array}{l}77.8 \% \text { with good to } \\
\text { excellent cosmesis, } \\
2.2 \% \text { with fat } \\
\text { necrosis }\end{array}$ \\
\hline
\end{tabular}


Table 2 Patient selection criteria for accelerated partial breast irradiation (APBI)

\begin{tabular}{|c|c|c|c|c|c|c|c|c|c|}
\hline Organization & $\begin{array}{l}\text { Age } \\
\text { (years) }\end{array}$ & $\begin{array}{l}\text { Tumor size } \\
(\mathrm{cm})\end{array}$ & $\begin{array}{l}\text { Lymph node } \\
\text { status }\end{array}$ & LVSI & Margin & Multifocality & DCIS & $\begin{array}{l}\text { Neoadjuvant } \\
\text { therapy }\end{array}$ & Histology \\
\hline \multicolumn{10}{|l|}{ ASTRO [15] } \\
\hline Suitable & $\geq 60$ & $\leq 2$ & $\mathrm{pNO}\left(\mathrm{i}^{+} / \mathrm{i}^{-}\right)$ & No & $\begin{array}{l}\text { Negative } \\
\quad(\geq 2 \mathrm{~mm})\end{array}$ & $\begin{array}{l}\text { Clinically } \\
\text { unifocal }\end{array}$ & None & None & IDC \\
\hline Cautionary & $50-59$ & $2.1-3.0$ & - & Limited/focal & Close $(<2 \mathrm{~mm})$ & $\begin{array}{l}\text { Clinically } \\
\text { unifocal }\end{array}$ & $\leq 3 \mathrm{~cm}$ & - & ILC \\
\hline Unsuitable & $<50$ & $>3$ & $\geq \mathrm{pN1}$ & Extensive & Positive & Multifocal & $>3 \mathrm{~cm}$ & Used & - \\
\hline ASBS [16] & $\geq 45$ & $\leq 3$ & No & - & Negative & - & $\leq 3 \mathrm{~cm}$ & - & IDC or DCIS \\
\hline ABS [17] & $\geq 50$ & $\leq 3$ & No & - & - & Unifocal & - & - & IDC \\
\hline
\end{tabular}

LVSI lymphovascular space invasion, DCIS ductal carcinoma in situ, ASTRO American Society of Therapeutic Radiation Oncology, pNi pathologically positive node determined by immunohistochemistry with a size $\leq 0.2 \mathrm{~mm}$, IDC invasive ductal carcinoma, ILC invasive lobular carcinoma, - not mentioned, ASBS American Society of Breast Surgeons, ABS American Brachytherapy Society

compared with the placement of catheters in interstitial brachytherapy (Fig. 1a). Between 2002 and 2004, 97 institutions participated in a registry trial, which was designed to collect data on the use of MammoSite ${ }^{\circledR}$. Collectively named the American Society of Breast Surgeons (ASBS) Registry Trial, a total of 1449 patients with early-stage breast cancer were treated using 34 Gy in 10 BID fractions. At a median follow-up of 60 months, only $2.6 \%$ of the patients developed an ipsilateral breast tumor recurrence, and $90.6 \%$ had good or excellent cosmesis score. The rates of complications were low with a reported $2.3 \%$ of fat necrosis and $13 \%$ of symptomatic seromas [18]. In a separate analysis, the rate of axillary failure in the same registry of patients was $0.79 \%$ with a 5 -year overall survival (OS) rate of $77.8 \%$ in patients with an axillary failure [19]. Additionally, 194 of the patients in the MammoSite ${ }^{\circledR}$ registry trial were treated with a diagnosis of DCIS. Long-term follow-up with a median of 54.4 months showed only a $3.1 \%$ rate of ipsilateral breast tumor recurrence [20].

As MammoSite ${ }^{\circledR}$ became increasingly popular, some of its shortcomings also became apparent. Given its singlelumen catheter, dosimetric shaping and conformation to the surrounding tissue can be challenging. This led

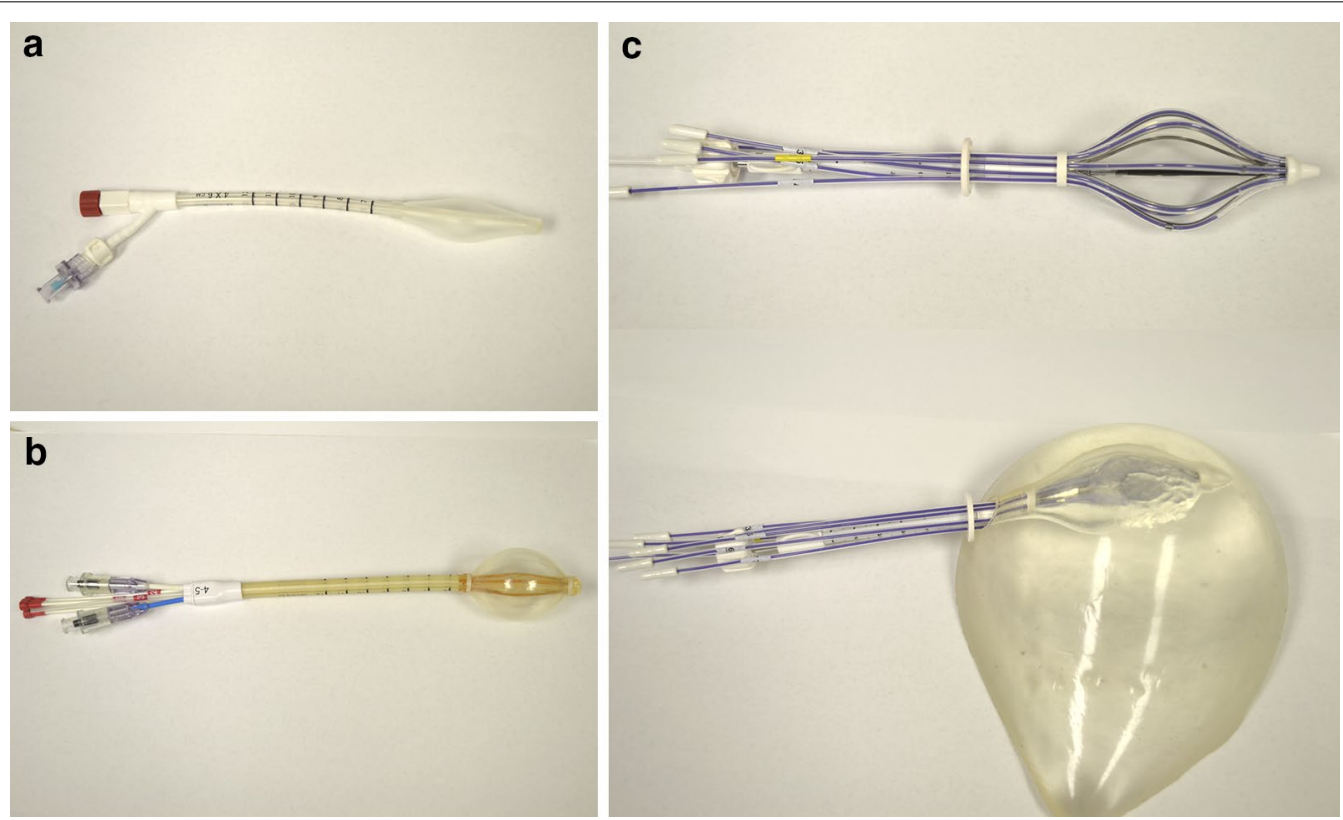

Fig. 1 Single- and multi-lumen/multi-catheter applicators used in accelerated partial breast irradiation. a An inflated 4X6 MammoSite ${ }^{\circledR}(\mathrm{Hologic}$ Bedford, MA, USA) balloon. b An inflated 4-5 Contur ${ }^{\circledR}$ (SenoRx, Inc., Aliso Viejo, CA, USA) balloon. c An expanded SAVI ${ }^{\circledR}$ (Cianna Medical, Aliso Viejo, CA, USA) 8-1 balloon (top) and placed in plastic model (bottom) 
to the development of other multi-lumen balloon-based catheters, including MammoSite $\mathrm{ML}^{\circledR}$ (Hologic, Bedford, MA, USA) and Contura ${ }^{\circledR}$ (SenoRx, Inc., Aliso Viejo, CA, USA). As opposed to the original MammoSite ${ }^{\circledR}$ balloon, which included a single lumen surrounded by an inflatable balloon, the Contura ${ }^{\circledR}$ balloon includes a central catheter and four surrounding fixed struts (Fig. 1b). Several dosimetric studies quickly showed lower dose delivered to organs at risk (OARs) using multi-lumen applicators than using single-lumen applicators. Cuttino et al. [21] compared the dose to the skin and chest wall for 43 patients treated with interstitial multicatheter technique, 45 treated with Contura ${ }^{\circledR}$, and 83 with MammoSite ${ }^{\circledR}$ and observed higher maximum skin and rib doses by MammoSite ${ }^{\circledR}$ compared with those by the multi-lumen techniques. In another study, Brown et al. [22] compared 33 patients treated with Contura ${ }^{\circledR}$ with 33 patients treated with MammoSite ${ }^{\circledR}$. Despite closer skin spacing, the Contura ${ }^{\circledR}$ technique showed lower median skin dose, lower rib dose, and equal or better planning target volume (PTV) coverage as compared with the MammoSite ${ }^{\circledR}$ technique. Clinical outcome data using MammoSite ${ }^{\circledR}$ have also been promising, with a single-institution series reporting an ipsilateral breast tumor recurrence rate of $2 \%$, no grade $3-4$ toxicities, and good/excellent cosmetic outcome in $97 \%$ of 46 patients at a median follow-up of 36 months [23].

To allow even more dosimetric flexibility, Strut Adjusted Volume Implant $\left(\mathrm{SAVI}^{\circledR}{ }^{\circledR}\right.$, Cianna Medical, Aliso Viejo, CA, USA) was developed which included a central catheter surrounded by 6,8 , or 10 peripheral catheters (Fig. 1c). Initial results using SAVI ${ }^{\circledR}$ have been excellent dosimetrically, with evaluation of 102 patients treated revealing target volume receiving $90 \%$ of prescribed dose (V90) of $95.9 \%$ and maximum median skin dose of $75 \%$ of prescribed dose [24]. At a median follow-up of 21 months, the ipsilateral breast tumor recurrence rate was $1 \%$, and the rate of symptomatic seroma or fat necrosis was $1.9 \%$, showing low rates of toxicity and recurrence in carefully selected patients consistent with other B-APBI data.

\section{Technique and catheter placement}

Since the use of multi-catheter interstitial brachytherapy has declined dramatically in the recent past and is only reserved to few specialized centers, this section will instead focus on placement of single- and multi-lumen applicators $\left(\right.$ MammoSite ${ }^{\circledR}$, Contura ${ }^{\circledR}$, and $\left.\mathrm{SAVI}^{\circledR}\right)$. Initial techniques for insertion of the MammoSite ${ }^{\circledR}$ balloon required placement either at the time of lumpectomy (open-cavity technique) or as a separate procedure (closed-cavity technique) up to 10 weeks after operation. If placed postoperatively, the device can then be inserted either through the surgical scar or through a separate incision. Ultrasound guidance is frequently used to detect the seroma, which in most cases associates with the actual tumor bed and aligns the route of insertion along the longest axis diameter of the cavity. Some institutions obtain a computed tomography (CT) scan several days before insertion of the catheter to measure the size of the cavity and estimate the needed device size. After insertion, the balloon is then inflated with sterile saline to a diameter of $4.0-5.0 \mathrm{~cm}$, and a small amount of radiographic material is added for contrast enhancement. A CT scan is then obtained after placement of the balloon to evaluate the conformance of the balloon to the cavity and absence of air or fluid gaps. A ratio of air or fluid in the cavity to balloon surface of less than $10 \%$ is usually deemed acceptable, and a balloon-skin distance equal or greater than $5 \mathrm{~mm}$ is ideal. The lumpectomy cavity is then delineated and expanded by $1 \mathrm{~cm}$ to define the PTV. Each expansion and PTV should conform to the patient's anatomy, stay $5 \mathrm{~mm}$ from the skin, and remain at the edge of the pectoralis muscles and ribs. The most commonly prescribed dose is 3.4 Gy BID to a total of 34 Gy. Although normal tissue constraints can vary from institution to institution, the maximum allowable skin dose is kept below $100 \%$ of the prescription. If the balloon-skin distance is $5-7 \mathrm{~mm}$, up to $145 \%$ of the prescribed dose is also acceptable. Ideally, $95 \%$ of the PTV should receive $95 \%$ of the prescribed dose, and V150 and V200 (volumes of tissue receiving $150 \%$ and $200 \%$ prescribed dose) should be limited to 50 and $20 \mathrm{cc}$, respectively. It is recommended that conformance and balloon-skin distance be assessed daily before each treatment session. The placement and dosimetric constraints of the Contura ${ }^{\circledR}$ and SAVI ${ }^{\circledR}$ balloons follow a similar protocol.

\section{External beam APBI}

As B-APBI was slowly growing in popularity, its use was still limited to centers with brachytherapy expertise and access to LDR or HDR afterloaders. If the rationale for B-APBI holds true that in the majority of early-stage breast cancer patients the risk of recurrence is limited to the area surrounding the lumpectomy cavity, then the same should hold true for treatment using external beam. Nevertheless, external beam APBI (EB-APBI) is not a relatively new concept, and some of the earliest trials using EB-APBI date back to as early as 1980s. Ribeiro et al. [25] randomized 708 patients who were treated at Christie Hospital between 1982 and 1987 to undergo WBI to 40 Gy in 15 fractions or tumor bed-only irradiation using electrons to $40-42.5$ Gy in eight fractions. After a median follow-up of 5.4 years, the ipsilateral breast tumor recurrence rate was $15 \%-34 \%$ for patients who underwent limited field irradiation compared with 
$8 \%-14 \%$ for patients who underwent WBI depending on the pathology. They noted that even though limited field electron irradiation was feasible, the local recurrence rate was higher than that of patients who underwent WBI, and better patient selection and treatment techniques were needed to improve outcomes. In another similar study, Dodwell et al. [26] randomized patients to undergo WBI to 40 Gy in 15 fractions or APBI to 55 Gy in 20 fractions using electrons. The study accrued only 174 out of expected 400 patients and closed early due to nonaccrual. Although this limited any definitive conclusions that can be drawn from this study, the differences in the rates of ipsilateral breast tumor recurrence (WBI $4 \%$ vs. APBI 12\%), locoregional failure (WBI 24\% vs. APBI 9\%), distant metastases (WBI $27 \%$ vs. APBI $23 \%$ ), or OS (WBI $73 \%$ vs. APBI $70 \%$ ) were not significant.

More recently, the most significant EB-APBI trial to date, named the Randomized Trial of Accelerated Partial Breast Irradiation (RAPID), released its interim cosmesis and toxicity analysis, showing higher rates of adverse cosmesis and late radiation toxicity in the EBAPBI group compared with the WBI group [27]. In this study, 2135 patients with invasive ductal carcinoma (IDC) or DCIS with tumor size $\leq 3 \mathrm{~cm}$, negative surgical margins, negative nodes determined by pathologic assessment, and older than 40 years were randomized to either WBI to 42.5 Gy in 16 fractions or 50 Gy in 25 fractions or EB-APBI to 38.5 Gy in 10 BID fractions of 3.85 Gy. In the WBI group, 21\% of the patients received boost to the tumor bed, and none in the EB-APBI group. After a median follow-up of 3 years, the EB-APBI group showed worse cosmetic outcome assessed either by trial nurse (33\% vs. $13 \%$ in the WBI group) or by patient selfassessment (32 vs. $21 \%$ in the WBI group). The rates of grade 1-2 toxicity were higher in the EB-APBI group than in the WBI group. Although other non-randomized single- and multi-institution experiences from William Beaumont [28], RTOG 0319 [29], and Rocky Mountain Cancer Center [30] have shown good local control and cosmetic outcome, the results of the RAPID trial [27] have added to previous experiences from Tufts University [31] and University of Michigan [32] that had called into question the unacceptable rates of cosmesis and toxicity using EB-APBI. Therefore, at this point we do not recommend using EB-APBI outside of the settings of a clinical protocol.

\section{Intraoperative APBI}

Intraoperative APBI (IO-APBI) has been a new and exciting development in APBI. The two most extensively studied devices capable of delivering IO-APBI are the Intrabeam ${ }^{\circledR}$ device (Oberkochen, Germany) and the Novac $7^{\circledR}$ device (Hitesys, Latina, Italy). Intrabeam ${ }^{\circledR}$ produces low-energy photons up to $50 \mathrm{kV}$ using spherical applicators of varying sizes with intraoperative treatment duration of approximately $30 \mathrm{~min}$. In the recently updated targeted radiation therapy trial (TARGIT-A), an international cohort of participants enrolled 3451 patients who were randomized to either conventional WBI per each center's protocols or IO-APBI using Intrabeam ${ }^{\circledR}$, with a single 20 Gy fraction immediately after lumpectomy prescribed to the surface of the applicator (about 5-7 Gy at $1 \mathrm{~cm}$ ) [33]. If the patients had predefined adverse pathologic features including LCIS, lymphovascular space invasion, positive nodal status, or other parameters defined at each center, postoperative WBI was added, and the IO-APBI was counted as the boost. With a primary endpoint of local recurrence, the non-inferiority of IO-APBI was set at a $2.5 \%$ absolute difference in local recurrence. At a median follow-up of 2 years and 5 months, the IO-APBI group showed a local recurrence rate of $3.3 \%$ vs. $1.3 \%$ in the WBI group $(P=0.04)$, meeting the non-inferiority criteria. Additionally, the rates of OS or distant metastases were not significantly different, and the IO-APBI group also showed low rates of grade $3-4$ skin toxicity.

The Novac $7^{\circledR}$ device has been evaluated in the Milan Electron IntraOperative Trial (ELIOT) study [34]. The device is a mobile accelerator capable of generating different electron energies ranging from 4 to $12 \mathrm{MeV}$. In this trial, 1305 patients were randomized either to conventional WBI or to receive a single fraction of intraoperative electrons to a dose of 21 Gy prescribed to the tumor bed. The target was surgically constructed, and the thoracic shielding was placed underneath the target. The total delivery duration was $30-40 \mathrm{~min}$. Inclusion criteria included age $>48$ years and tumor diameter $\leq 2.5 \mathrm{~cm}$ in women who were eligible for BCS. After a median followup of 5.8 years, 35 patients in the IO-APBI group and 4 in the WBI group experienced ipsilateral breast tumor recurrence $(P<0.0001)$, equaling 5 -year event rates of $4.4 \%$ vs. $0.4 \%$. The OS rate was similar between the two groups and the rate of skin adverse effects was significantly lower in the IO-APBI group than in the WBI group $(P=0.0002)$.

Although the above IO-APBI trials show some promising early results, the follow-up for both trials is relatively short especially given that breast cancer can recur many years later. Other logistical issues also exist such as limited knowledge of tumor pathology at the time of the surgery and high local recurrence rates seen in the ELIOT study. Additionally, the patients in these trials were highly selected, and it is unclear if IO-APBI can be considered a therapeutic option in any other group of earlystage breast cancer patients. Nevertheless, these studies have paved the way for future investigations into the use 
of IO-APBI. Given that it is extremely convenient for the patients and delivered in a single fraction at the time of the surgery, IO-APBI could be a reasonable option for a small subpopulation of early-stage breast cancer patients.

\section{Selection criteria}

To date, there have been no randomized trials comparing WBI with B-APBI. As such, specific criteria that are deemed universally acceptable for patients who are appropriate for B-APBI are not known. In the early days of interstitial APBI, since the criteria had not yet been determined, the majority of patients treated were those with early-stage breast cancer. This trend continued to the era of single- and multi-lumen applicators. Through many years of cumulative experience, certain trends have started to emerge about which group of patients can safely undergo B-APBI. Therefore, professional societies, including the American Society of Therapeutic Radiation Oncology (ASTRO) [15], the American Society of Breast Surgeons (ASBS) [16], and the American Brachytherapy Society (ABS) [17], have put forward their own specific recommendations about which patients can be safely treated with APBI (Table 2). Of note, these recommendations apply to all forms of APBI, including EB-APBI and IO-APBI, which will be discussed below. As can be seen from Table 2, ASTRO recommendations are divided into three categories labeled "suitable," "cautionary," and "unsuitable". We recommend only treating patients under the suitable or those limited to one or two cautionary features off of a randomized protocol.

It is also worthwhile mentioning that even though the above societies deemed the use of APBI acceptable in certain patient populations, a joint statement from three German oncology societies recommended refraining from APBI use outside of a prospective study [35]. They felt that there were not enough data available at the time to draw any conclusions about its safety and that it will also decrease the number of women who could be enrolled in ongoing prospective studies [35].

\section{Controversies in APBI}

In 2012, Smith et al. [36] reported that based on their retrospective review of the surveillance, epidemiology, and end results (SEER)-Medicare database, women who underwent APBI between 2003 and 2007 had a higher rate of subsequent mastectomy than those who underwent WBI $(3.95 \%$ vs. $2.18 \%, P<0.001)$. APBI treatment was also more frequently associated with higher rates of infectious and non-infectious postoperative complications, breast pain, fat necrosis, and rib fracture than WBI. The 5-year OS rate however did not differ between the two groups. In a follow-up report, Smith et al. [37] stratified the same population of patients treated with APBI based on the ASTRO consensus guidelines into the suitable, cautionary, and unsuitable groups. Overall, APBI did result in a significant reduction in the risk of mastectomy as compared with lumpectomy alone ( $2.8 \%$ vs. $4.7 \%)$. However, the risk reduction was not significant as compared with WBI (2.8\% vs. $1.3 \%)$. Stratification based on the ASTRO suitability criteria did not show a difference in the relative risk of mastectomy $(P=0.84)$, although suitable patients overall had a low absolute risk of mastectomy after APBI (1.6\%).

It is important to keep in mind several limitations of the above studies. The limitations of retrospective studies are self-evident. Furthermore, mastectomy was used as a surrogate end-point since ipsilateral breast tumor recurrence itself is not listed in the SEER-Medicare database and a subsequent mastectomy can be due to a number of reasons unrelated to ipsilateral breast tumor recurrence. Additionally, the period studied (2003-2007) was immediately after the approval of single- and multi-lumen applicators, with many investigators using the device for the first time so it is reasonable to expect relatively higher rates of complications such as infections and fat necrosis.

Another rising area of controversy in breast radiation oncology involves the use of IO-APBI, to the point now that it has garnered national attention as reported on the Wall Street Journal [38]. Some of the controversy surrounds the rising rates of use of IO-APBI given its convenience in one intraoperative fraction and low cost burden to the health care system while questions regarding its safety and efficacy still remain. Some of the issues raised in the ELIOT trial include a significantly higher relapse rate in the IO-APBI group compared with the WBI cohort, no accounting for adverse features on final pathology such as positive margin, higher rates of fat necrosis with IO-APBI, and final cosmesis analysis being performed on only a subset of the patients [39]. The TARGIT-A study has also faced multiple criticisms, such as the excess non-breast cancer deaths and an increased rate of secondary malignancy in the WBI group, both of which usually need much longer-term follow-up to ascertain their significance [39].

Although the points raised in the above studies require consideration, the main questions about safety and efficacy of APBI can only be answered in the ongoing randomized clinical trials.

\section{Future directions}

APBI has now become a mainstay of treatment as part of the BCT algorithm. Even though it's only a suitable option and should only be considered in patients with early-stage breast cancer based on the consensus statements discussed above, it provides a much faster and convenient alternative to WBI. However, definitive data from randomized 
controlled trials, which are still ongoing, are needed. The most important of which, NSABP B-39/RTOG 0413 [40] is now closed to accrual. In this trial, WBI to 50-50.4 Gy in 25-28 fractions with an optional 10-16 Gy boost is compared with 34 Gy in 10 fractions delivered either via interstitial brachytherapy, MammoSite ${ }^{\circledR}$, MammoSite ML ${ }^{\circledR}$, or $\mathrm{SAVI}^{\circledR}$ or with EB-APBI to a dose of 38.5 Gy in 10 fractions delivered using 3-dimensional conformal radiation therapy. The selection criteria include patients with stage 0 , I, or II breast cancer resected by lumpectomy and with no more than three histologically positive nodes. The primary endpoint of the study is time to diagnosis of ipsilateral breast tumor recurrence with secondary endpoints including $O S$ and recurrence-free survival.

There are also other ongoing trials, including a study examining ultrashort-course APBI using Contura ${ }^{\circledR}$ (7 Gy $\times 4$ fractions) [41], the RAPID trial awaiting for final results, release of matured data of the TARGIT and ELIOT studies, and the randomized GEC-ESTRO trial [42]. With most of these trials approaching maturation, the exact role of APBI in the BCT paradigm will be further solidified. Additionally, the appropriate group of patients who can benefit from different APBI modalities will be elucidated, allowing shorter treatment duration, better toxicity profiles, and considerable savings to the health care system [43].

\section{Authors' contributions}

MA aided in drafting and composing the final manuscript. BST aided in drafting and composing the final manuscript. All authors read and approved the final manuscript.

\section{Author details}

${ }^{1}$ Department of Radiation Oncology, Houston Methodist Hospital, Cancer Center and Research Institute, Weil Cornell Medical College, 6565 Fannin, Ste\#DB1-077, Houston, TX 77030, USA. ${ }^{2}$ Department of Radiation Oncology, The University of Texas Medical Branch at Galveston, Houston, TX 77555, USA.

\section{Competing interests}

The authors declare that they have no competing interests.

Received: 2 October 2015 Accepted: 2 February 2016

Published online: 24 March 2016

\section{References}

1. Fisher B, Anderson S, Redmond CK, Wolmark N, Wickerham DL, Cronin WM. Reanalysis and results after 12 years of follow-up in a randomized clinical trial comparing total mastectomy with lumpectomy with or without irradiation in the treatment of breast cancer. N Engl J Med. 1995;333(22):1456-61.

2. Veronesi U, Cascinelli N, Mariani L, Greco M, Saccozzi R, Luini A, et al. Twenty-year follow-up of a randomized study comparing breast-conserving surgery with radical mastectomy for early breast cancer. N Engl J Med. 2002;347(16):1227-32.

3. van Dongen JA, Voogd AC, Fentiman IS, Legrand C, Sylvester RJ, Tong $D$, et al. Long-term results of a randomized trial comparing breastconserving therapy with mastectomy: European Organization for Research and Treatment of Cancer 10801 trial. J Natl Cancer Inst. 2000;92(14):1143-50.
4. Ballard-Barbash R, Potosky AL, Harlan LC, Nayfield SG, Kessler LG. Factors associated with surgical and radiation therapy for early stage breast cancer in older women. J Natl Cancer Inst. 1996;88(11):716-26.

5. Kuske RR Jr. Breast brachytherapy. Hematol Oncol Clin North Am. 1999;13(3):543-58.

6. Wazer DE, Kramer B, Schmid C, Ruthazer R, Ulin K, Schmidt-Ulrich R. Factors determining outcome in patients treated with interstitial implantation as a radiation boost for breast conservation therapy. Int J Radiat Oncol Biol Phys. 1997;39(2):381-93.

7. Wazer DE, Berle L, Graham R, Chung M, Rothschild J, Graves T, et al. Preliminary results of a phase I/II study of HDR brachytherapy alone for T1/T2 breast cancer. Int J Radiat Oncol Biol Phys. 2002;53(4):889-97.

8. Arthur DW, Koo D, Zwicker RD, Tong S, Bear HD, Kaplan BJ, et al. Partial breast brachytherapy after lumpectomy: low-dose-rate and high-doserate experience. Int J Radiat Oncol Biol Phys. 2003;56(3):681-9.

9. Benitez PR, Chen PY, Vicini FA, Wallace M, Kestin L, Edmundson G, et al. Partial breast irradiation in breast conserving therapy by way of interstitial brachytherapy. Am J Surg. 2004;188(4):355-64.

10. Strnad V, Ott O, Potter R, Hildebrandt G, Hammer J, Resch A, et al. Interstitial brachytherapy alone after breast conserving surgery: interim results of a German-Austrian multicenter phase II trial. Brachytherapy. 2004;3(3):115-9.

11. Ott OJ, Hildebrandt G, Potter R, Hammer J, Lotter M, Resch A, et al. Accelerated partial breast irradiation with multi-catheter brachytherapy: local control, side effects and cosmetic outcome for 274 patients. Results of the German-Austrian multi-centre trial. Radiother Oncol. 2007;82(3):281-6.

12. Strnad V, Hildebrandt G, Potter R, Hammer J, Hindemith M, Resch A, et al Accelerated partial breast irradiation: 5-year results of the German-Austrian multicenter phase II trial using interstitial multicatheter brachytherapy alone after breast-conserving surgery. Int J Radiat Oncol Biol Phys. 2011;80(1):17-24.

13. Fentiman IS, Deshmane V, Tong D, Winter J, Mayles H, Chaudary MA. Caesium(137) implant as sole radiation therapy for operable breast cancer: a phase II trial. Radiother Oncol. 2004;71(3):281-5.

14. Polgár C, Major T, Fodor J, Sulyok Z, Somogyi A, Lovey K, et al. Accelerated partial-breast irradiation using high-dose-rate interstitial brachytherapy: 12-year update of a prospective clinical study. Radiother Oncol. 2010;94(3):274-9.

15. Smith BD, Arthur DW, Buchholz TA, Haffty BG, Hahn CA, Hardenbergh PH, et al. Accelerated partial breast irradiation consensus statement from the American Society for Radiation Oncology (ASTRO). Int J Radiat Oncol Biol Phys. 2009;74(4):987-1001

16. The American Society of Breast Surgeons. Consensus Statement for Accelerated Partial Breast Irradiation. https://www.breastsurgeons.org/ statements/PDF_Statements/APBI.pdf. Accessed 15 Sept 2015.

17. Shah C, Vicini F, Wazer DE, Arthur D, Patel RR. The American Brachytherapy Society consensus statement for accelerated partial breast irradiation. Brachytherapy. 2013;12:267-77.

18. Vicini F, Beitsch P, Quiet C, Gittelman M, Zannis V, Fine R, et al. Five-year analysis of treatment efficacy and cosmesis by the American Society of Breast Surgeons MammoSite Breast Brachytherapy Registry Trial in patients treated with accelerated partial breast irradiation. Int J Radiat Oncol Biol Phys. 2011;79(3):808-17.

19. Aburabia M, Roses RE, Kuerer HM, Fine R, Beitsch PD, Goyal S, et al. Axillary failure in patients treated with MammoSite accelerated partial breast irradiation. Ann Surg Oncol. 2011;18(12):3415-21.

20. Jeruss JS, Kuerer HM, Beitsch PD, Vicini FA, Keisch M. Update on DCIS outcomes from the American Society of Breast Surgeons accelerated partial breast irradiation registry trial. Ann Surg Oncol. 2011;18(1):65-71.

21. Cuttino LW, Todor D, Rosu M, Arthur DW. A comparison of skin and chest wall dose delivered with multicatheter, Contura multilumen balloon, and MammoSite breast brachytherapy. Int J Radiat Oncol Biol Phys. 2011;79(1):34-8.

22. Brown S, McLaughlin M, Pope DK, Haile K, Hughes L, Isreal PZ, et al. A dosimetric comparison of the Contura multilumen balloon breast brachytherapy catheter vs. the single-lumen MammoSite balloon device in patients treated with accelerated partial breast irradiation at a single institution. Brachytherapy. 2011;10(1):68-73.

23. Israel PZ, Robbins A, Shroff P, Brown S, McLaughlin M, Pope K. Threeyear clinical outcome using the Contura multilumen balloon breast 
brachytherapy catheter to deliver accelerated partial breast irradiation (APBI): improving radiation standards for the optimal application of APBI. Brachytherapy. 2012;11(4):316-21.

24. Yashar CM, Scanderbeg D, Kuske R, Wallace A, Zannis V, Blair S, et al. Initial clinical experience with the Strut-Adjusted Volume Implant (SAVI) breast brachytherapy device for accelerated partial-breast irradiation (APBI): first 100 patients with more than 1 year of follow-up. Int J Radiat Oncol Biol Phys. 2011;80(3):765-70.

25. Ribeiro GG, Magee B, Swindell R, Harris M, Banerjee SS. The Christie Hospital breast conservation trial: an update at 8 years from inception. Clin Oncol (R Coll Radiol). 1993;5(5):278-83.

26. Dodwell DJ, Dyker K, Brown J, Hawkins K, Cohen D, Stead M, et al. A randomised study of whole-breast vs tumour-bed irradiation after local excision and axillary dissection for early breast cancer. Clin Oncol (R Coll Radiol). 2005;17(8):618-22.

27. Olivotto IA, Whelan TJ, Parpia S, Kim DH, Berrang T, Truong PT, et al. Interim cosmetic and toxicity results from RAPID: a randomized trial of accelerated partial breast irradiation using three-dimensional conformal external beam radiation therapy. J Clin Oncol. 2013;31(32):4038-45.

28. Chen PY, Wallace M, Mitchell C, Grills I, Kestin L, Fowler A, et al. Four-year efficacy, cosmesis, and toxicity using three-dimensional conformal external beam radiation therapy to deliver accelerated partial breast irradiation. Int J Radiat Oncol Biol Phys. 2010;76(4):991-7.

29. Vicini F, Winter K, Wong J, Pass H, Rabinovitch $R$, Chafe $S$, et al. Initial efficacy results of RTOG 0319: three-dimensional conformal radiation therapy (3D-CRT) confined to the region of the lumpectomy cavity for stage I/II breast carcinoma. Int J Radiat Oncol Biol Phys. 2010;77(4):1120-7.

30. Lei RY, Leonard CE, Howell KT, Henkenberns PL, Johnson TK, Hobart TL, et al. Four-year clinical update from a prospective trial of accelerated partial breast intensity-modulated radiotherapy (APBIMRT). Breast Cancer Res Treat. 2013;140(1):119-33.

31. Hepel JT, Tokita M, MacAusland SG, Evans SB, Hiatt JR, Price LL, et al. Toxicity of three-dimensional conformal radiotherapy for accelerated partial breast irradiation. Int J Radiat Oncol Biol Phys. 2009;75(5):1290-6.

32. Jagsi R, Ben-David MA, Moran JM, Marsh RB, Griffith KA, Hayman JA, et al. Unacceptable cosmesis in a protocol investigating intensity-modulated radiotherapy with active breathing control for accelerated partial-breast irradiation. Int J Radiat Oncol Biol Phys. 2010;76(1):71-8.

33. Vaidya JS, Wenz F, Bulsara M, Tobias JS, Joseph DJ, Keshtgar M, et al. Risk-adapted targeted intraoperative radiotherapy versus whole-breast radiotherapy for breast cancer: 5-year results for local control and overall survival from the TARGIT-A randomised trial. Lancet. 2014;383(9917):603-13.

34. Veronesi U, Orecchia R, Maisonneuve P, Viale G, Rotmensz N, Sangalli C, et al. Intraoperative radiotherapy versus external radiotherapy for early breast cancer (ELIOT): a randomised controlled equivalence trial. Lancet Oncol. 2013;14(13):1269-77.

35. Wenz F, Budach W, Dunst J, Petra F, Haase W, Harms W, et al. Accelerated partial-breast irradiation (APBI)-ready for prime time? Strahlenther Onkol. 2009;185(10):653-5.

36. Smith GL, Xu Y, Buchholz TA, Giordano SH, Jiang J, Shih YC, et al. Association between treatment with brachytherapy vs whole-breast irradiation and subsequent mastectomy, complications, and survival among older women with invasive breast cancer. JAMA. 2012;307(17):1827-37.

37. Smith GL, Jiang J, Buchholz TA, Xu Y, Hoffman KE, Giordano SH, et al. Benefit of adjuvant brachytherapy versus external beam radiation for early breast cancer: impact of patient stratification on breast preservation. Int J Radiat Oncol Biol Phys. 2014;88(2):274-84.

38. The Wall Street Journal. Alternative way to treat early-stage breast cancer with radiation. http://www.wsj.com/articles/alternative-way-to-treatearly-stage-breast-cancer-with-radiation-1440448587. Accessed 15 Sept 2015.

39. Moran MS, Truong PT. Intraoperative accelerated partial breast irradiation: caution still warranted. Int J Radiat Oncol Biol Phys. 2014;89(3):496-8.

40. Radiation Therapy Oncology Group. RTOG 0413/NSABP B-39 Study Protocol. http://www.rtog.org/members/protocols/0413/0413.pdf. Accessed 15 Sept 2015.

41. Khan AJ, Vicini FA, Brown S, Haffty BG, Kearney T, Dale R, et al. Dosimetric feasibility and acute toxicity in a prospective trial of ultrashort-course accelerated partial breast irradiation (APBI) using a multi-lumen balloon brachytherapy device. Ann Surg Oncol. 2013;20(4):1295-301.

42. Polgár C, Van Limbergen E, Potter R, Kovacs G, Polo A, Lyczek J, et al. Patient selection for accelerated partial-breast irradiation (APBI) after breast-conserving surgery: recommendations of the Groupe Europeen de Curietherapie-European Society for Therapeutic Radiology and Oncology (GEC-ESTRO) breast cancer working group based on clinical evidence (2009). Radiother Oncol. 2010;94(3):264-73.

43. Greenup RA, Camp MS, Taghian AG, Buckley J, Coopey SB, Gadd M, et al. Cost comparison of radiation treatment options after lumpectomy for breast cancer. Ann Surg Oncol. 2012;19(10):3275-81.

\section{Submit your next manuscript to BioMed Central and we will help you at every step:}

- We accept pre-submission inquiries

- Our selector tool helps you to find the most relevant journal

- We provide round the clock customer support

- Convenient online submission

- Thorough peer review

- Inclusion in PubMed and all major indexing services

- Maximum visibility for your research

Submit your manuscript at www.biomedcentral.com/submit
( Biomed Central 